\title{
METHODS FOR ECOLOGICAL DESING OF TECHNICAL PROCESSES AND SYSTEMS
}

\author{
Slobodan Stefanović ${ }^{1}$, Nadezda Šubara ${ }^{2}$, Radoje Cvejić ${ }^{3}$, Jasmina Stojiljković ${ }^{4}$ \\ College of Applied Professional Studies, Vranje, ${ }^{2}$ Railway High School, Belgrade, ${ }^{3}$ Faculty of strategic and \\ operational management, Belgrade, Serbia
}

\begin{abstract}
The basic concept (the default), the designer in design for manufacturing system is to integrate production equipment, transport means, equipment and harmonious introducing modern technology for monitoring systems and processes to integrate and manage computer equipment. The main technological machine projects must meet both general and mechanical conditions.
\end{abstract}

Key words: technical - mechanical projects, health and safety, plastic returnable materials.

\section{INTRODUCTION}

General conditions in the major mechanical and machine projects regulate relationships and responsibilities of participants in the implementation (construction) of technological systems:

- Assignment of works based on the law on the construction of the facility and its amendments,

- Conclusion of the contract between the investor and the contractor, review,

- All bidders receive a project for price, bidders,

- The offer must be included in the

- The investor assigns work best

- The contract is considered concluded when the parties declare in writing to build the plant and the price (cost, time, quality, method of payment, control ...),

- A natural person who works and manages a natural person for supervision,

- Deviations from the project permitted only with approval of planners,

- Building permits and water + energy,

- The warranty period for the quality of the installation (run from the technical preparations),

- Defects,

- Damages,
- Material that is installed must be new and of good quality,

- For smooth functioning of the system is responsible contractor,

- In the event that the proposed solution to a bad and wrong, the investor provides the change project,

- The estimate of the subsequent works, Attest, security measures, leading to construction and building log book,

- Must be carried out technical acceptance,

- There must be a project as built in three copies,

- The face of the supervision provided by the investor,

- The contractor is responsible only supervisory authority,

- Testing the contractor shall,

- A completed examination consists of the records,

- End: The contractor shall submit a written report to the supervisory authority of the completion of works,

- Technical examination (complete documentation),

- Commission for technical inspection of its opinion,

- Contractor removes the shortcomings found, authority,

- Permission to use a supervisory

- Probationary,

- The investor and the contractor after obtaining permission to use the facility are required to perform the statutory deadline and hand over the final settlement of all derivative works. 


\section{TECHNICAL REQUIREMENTS RELATING TO THE SPECIFIC PROJECT}

Prescribe the characteristics of the equipment is installed, installation requirements, type testing and installation, etc.

The practices are:

- Technical requirements for the installation of central heating

- Technical requirements for the installation of air conditioning and ventilation

- General technical requirements

- Specifications

- Technical requirements for city gas pipeline network

- Requirements for construction works

- Technical conditions of construction of city gas pipeline network of steel pipes

- Technical conditions of construction measuring and regulating stations for gas

- Specification for general piping installation

- Technical requirements for the installation of a divorce cold, producing hot water and hot

- Technical installations for divorce by conditions komprimanovog air

\section{CONTRIBUTION OF THE PROJECT APPLIED SAFETY MEASURES}

Protection Act at work relates to the field of labor relations, environmental protection, personal work, etc. The concept of safety includes appropriate measures whose implementation ensures the protection of life and health at work, the working environment of health and safety risks.

ZNR enjoy all persons who are in any respect the legal and physical entities. Provision of ZNR is an obligation, which can be realized starting from the design of the building, facilities and installations, through their construction and use.

The prescribed measures to protect the dignitary included in the technical documentation and made it into the special favor of the measures applied ZNR.
Safety measures can be classified into three groups:

- General - the ones that apply to all assignments in all business activities (health conditions, noise and vibration, transportation, movement of workers, the effect of electrical energy, damaging radiation, hazardous and noxious substances, first aid worker, investment structures, tools to work, rescue workers and resources for personal protection ...)

- Special measures ZNR - determine for specific types of technological processes and operations that can be considered general. The positions at which the next application of safety measures during design, construction and use of buildings can't eliminate the risk of injury and occupational disease having the character of places with special conditions for work.

- Preliminary measures ZNR - relate to investment structures designed to support and work rooms, facilities where the investment process work takes place outdoors (tools for working in the mechanized plant), as well as means for personal protection.

The special contribution of the project measures to protect the work, made for each type of project (building - architectural, machine - technological, electrical ...) and signed by the responsible planners for each area. Each contribution should include:-a list of all the risks and hazards related to the purpose facility that can occur during construction and operation - provides for measures to eliminate these dangers and hazards, and regulations that cause - general notes and obligations - Conclusion.

In addition to special reports on health and safety, the project may include a special report on the measures applied to protect against fire, if there is a special nature of the technological process of an increased risk of having stirred up.

The fire protection measures include: ways to prevent the occurrence of fires, fire alarm systems, fire alarm systems for hazardous concentrations of flammable gases or vapors, fire hydrant systems to protect against the cellular anti-fire equipment. 


\section{METHODS OF DESIGNING TECHNOLOGICAL - ECOLOGICAL SYSTEMS FOR THE TREATMENT OF RETURNABLE PLASTIC MATERIJALS}

The term" plastic" refers to the specific properties of matter plasticity - the ability to create. In many languages, commonly referred to as" artificial" material, but also the nature of plastics products (peat, tar, natural rubber, etc.) Plastic can be obtained from many natural materials and most of the hydrocarbons. One tenth of refined crude is used for the production of plastic materials. Plastic materials are used for years for packaging, although a problem in terms of environmental protection. The reasons for increasing the use of low cost raw materials, low weight and different possibilities of technology. The specific energy consumption (per unit of packed product) is much lower for the production of plastic packaging materials, as compared to glass or Aluminum.

The basic problem of feedback plastic materials (plastic waste) is that most often ends up on landfill disposal (often due to human impact and other external influences). Dumps a large number of cities in developed countries practically are completed and new ones (due to high prices) does not build the right speed.

For plastic packaging waste, this waste is removed with a way particularly unfavorable due to taking a large space (large volume), non-compostable under the influence of atmospherically changes, especially from the standpoint of energy loss (indefinitely) for obtaining new materials related to polymers. In our country there are no conditions for the collection, sorting and efficient processing of plastic waste. Theoretically, from the ecological standpoint, it is not wrong use of synthetic materials, with regard to plastic bags and other products can be used several times, and it is feasible and recycling. In current conditions, however, and organized recycling of plastic materials, waste collection and disposal of prescribed, plastics can't be regarded as neutral for the environment.
Synthetic materials are separated in the thermoplastic (soften at high temperatures, thermostable plastics) resistant to high temperatures (with an increase in heat curing) and elastomers, which are elastic and Foamed materials (like rubber). All three types of synthetic material combustion, developing high temperature and this feature can be applied for recycling, with caution when burning PVC, must not allow spreading through the chlorides. (Come) into the atmosphere. From the ecological point of view, recycling of synthetic materials is acceptable, since it can't be re-used even hard plastic bottles.

Another solution is to replace PVC with PET (PETE) - unipolimer plastic, which could be recycled indefinitely if the organized collection of used mass. To produce one (PET) bottles must be $60 \%$ of energy used in glass or $25 \%$ of the energy needed to manufacture aluminum cans. These economic initiative are significant from the standpoint of what the empty bottle can produce goods for other purposes, e.g. in the U.S. are made from recycled bottles for cable insulation, new bottles, foil, etc.

Plastics used in the household (since they are not naturally degradable) require the research and solutions for natural disintegration in a manner similar to the degradation of other organic matter. The latest experiments are built out of plastic bags of natural sugar (bio-degradable and are degraded to a purely natural way bacteriologically). This solution is still in research phase, I expect good results and extensive application. This could be the primary way of utilization of waste plastic, and a secondary combustion. Synthetics from natural, renewable sources appears again in some products in construction. Their basis is not a hydrocarbon, but the natural materials as well as jazein, formalin, cellulose, natural rubber, natural asphalt, tar or bitumen. They can be regarded as renewable materials and plastic products are not harmful to the environment. Hydrocarbons with time will surely expensive (impoverishment of stock) and researchers are new natural resources. Until then you can use the environmental 
benefits of synthetics such as good thermal insulation, light weight and durability for which they can't compete with traditional materials. Green plan favors simple recycled materials that have special properties, but with a compromise between the possible environmental damage and safe use.

Products from plastic materials are of current use, but creates long-term problem for the environment. Amount of plastic materials in municipal waste are very great, the CONSIDERATIONS Liquid from households account for $30 \%$. Since the plastic is not dissolved and remains as a solid mass, increases the amount and volume of waste. (PVC) is made up of many plastic materials, obtained by the polymerization of vinyl chloride, which is a toxic gas and the toxicity is very problematic. From vinyl chloride plastics are slowly released into the air and sealed in food, and slowly destroys the liver, nervous system and totally destroys the testes and immunity. Because of the toxic additives such as phthalate (Phthalate) lead and kadminum (PVC) are difficult to recycle. If a ignite $1 \mathrm{~kg}$ (PVC)-A mass, relieve the amount of $0.5 \mathrm{~kg}$ chloro acid.

PC polycarbonate plastics used to manufacture bottles for child nutrition, kitchen, microwave ovens, the inner lining cans and plastic polytetraflourethylene (PTFE), known as taflon are toxic polymers. Unfortunately, the desire for profit in the market enabled the development of some new types of polymers. The only question is when will the time be scientifically proven and discover that the toxic elements from the packaging into the water crossing.

Plastic bottles in Serbia, although the light cover even $30 \%$ is the decay lifetime longer than 100 years. And there are allegations of large profits from the so-called (so called), PET (PETE) packaging (polyethylene terephthalate), but for us, these problems are still not considered. (Unlike other European states and known standards). It is believed that only make the plastic bottles because of the large volume and that does not pollute the environment. The data show that only registered Serbia wastes (other locations are not considered) daily amount of PET bottles - 100 tons! If all this division with 50 grams of weight which is the bottle, get the information that we have a daily two million plastic bottles. The biggest problem in Serbia is an organized collection of reuse PET bottles. In 2005 we imported the 34.000 tons of granulate for PET bottles as part of municipal waste occupy a large volume of our landfills.

The biggest problems occur if there is burning, where the stand is very toxic gases. Preventive methods are implemented projects and recycling facilities in order to protect ecosystems and irreplaceable economic effects. Discarded bottles are a major problem of our rivers. Going to the hydro power plant at the Danube Kalda inflict huge amounts of PET bottles.

Plastic bottles, containers and other packaging are one of the oldest and most fully realized systems for labeling. Although the world uses more system identification, one can say that they all generally based on the standard (ISO 1043 -1) with small modifications to the look and it is given in the table 1 .

Symbols are important users of dual indicating whether packaging can be recycled, recyclers and the type and characteristics plastic matter. 
Table 1. Symbol and meaning

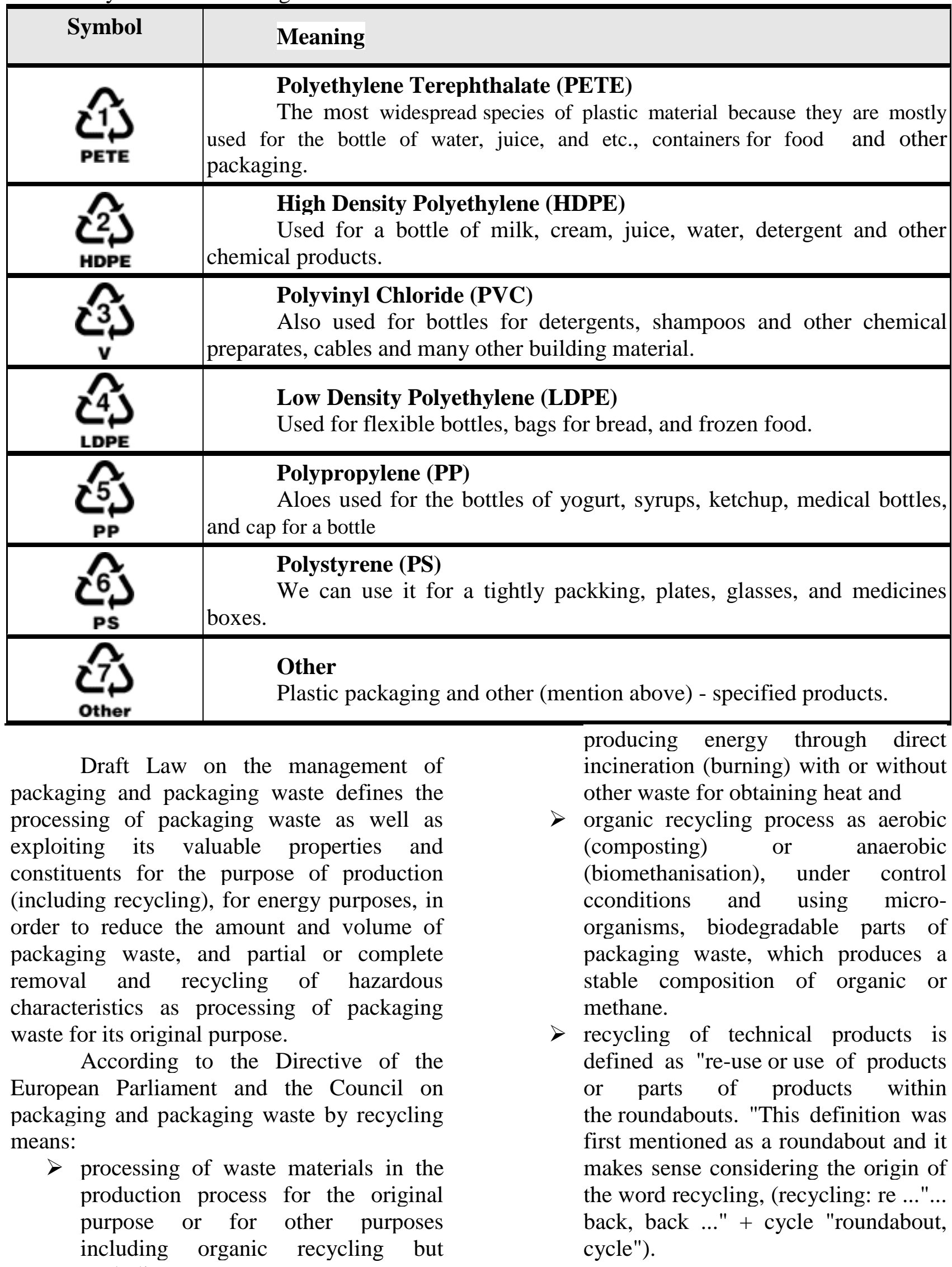




\section{DESING PROCESS FOR RECYCLING PLASTIC METERIALS}

Plastic materials back into solid form mixed with other types of materials in municipal solid waste (heterogeneous) were very dirty. For the purpose of recycling, it is necessary to collect and prepare. In the preparation, plastic waste is separated from the other, identify and separate the species. In the recycling process is crushed, washed, dried and re granulate processed and the packaging or in some other products. To perform these operations require specific equipment, obtaining a set of recycled materials. It was found that the whole process of treatment was less expensive and simpler if the plastic waste material collected by a separate, containers. Allocation of necessary materials from the waste can be organized in or by the citizens themselves (in households, schools, shops, non-manufacturing businesses, streets, etc..).

And centralized system of special plants (plants with a complete technological line).

\section{DIFFERENTIATING FEEDBACK PLASTIC MATERIALS}

The recycling process is the most important similarity material. As a rule, can be achieved relatively expensive previous classification. To obtain high-quality plastics, should be processed only homogeneous plastic mass. Separation of plastic materials can be divided into identification and separation:

IDENTIFICATION, characterization and complete identification of plastic materials is a very big task that requires complex analytical procedures and the most modern equipment. In some cases, however, it takes only an approximate estimate or determines the type of the tested plastic material. Developed and adopted a simple and rapid method of identification. Recognition of used packaging polymer is easiest if it is the symbol for recycling with the listed types of polymer materials it is made.

SEPARATION sorted plastics and crushed plastic material is performed according to him caused by physical properties such as density, connectivity, and electrical conductivity.

For the industry are of particular importance to the procedures based on differences in density. Using these procedures can be a mixture of plastics separated fractions and up to $98 \%$ purity. Difficulties arise in the separation of soft (PVC) type. Principle hydrocyclone technique is based on the separation of fractions of different specific weight (density) in the action of centrifugal force. In addition to these methods of separation are known methods of separation and flotation, separation based on different electrical conductivity (electrostatic device for sorting), etc.

Used plastic products can be reused or processed by different processes (depending on the goal, but also because of the reduction of the deposited mass) and a number of ways (see Figure 1:

- melting, with no change or little change macromolecular structures,

- chemical, hydrolysis and alcohol are available monomers, or hydrogenation of the starting material can get organic raw materials such as gases and oils,

- $\quad$ controlled burning, from which you get heat and combustion products are carbon dioxide $\left(\mathrm{CO}_{2}\right)$ and water $\left(\mathrm{H}_{2} \mathrm{O}\right)$. 


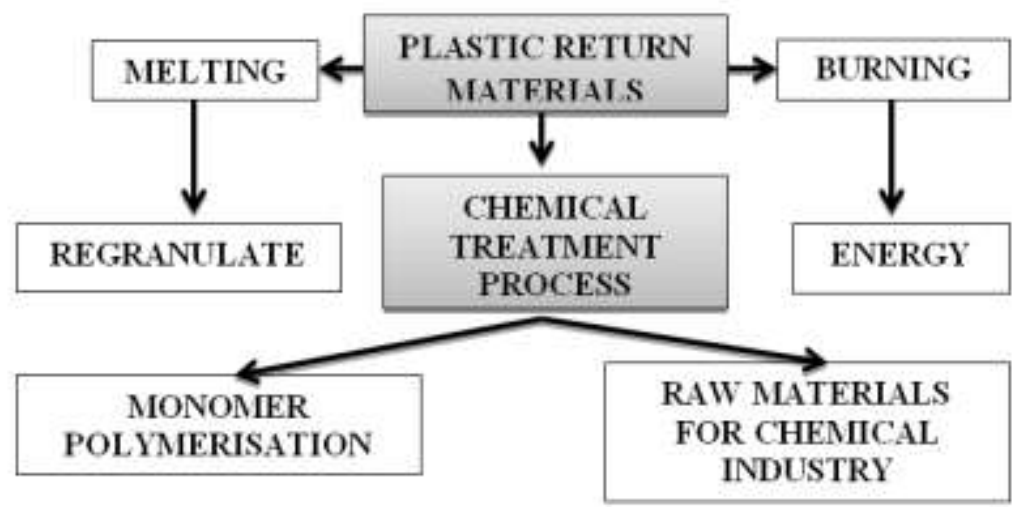

Picture 1: Treatments of plastics feedback matters.

Processing of fusion. Re granular molding is one of the oldest and most common methods of recycling. The basis of this method of recycling is the ability to remelt as much as possible with the thermoplastic.

\section{CHEMICAL TREATMENT PROCESSES ARE GROUPED INTO TWU GROUPS}

The first group of chemical treatment processes include chemical reactions which are macromolecular (polymers) are translated into low molecular weight substances. Thus, the obtained polymers or poly condensation reactions poly addition method to recycle the starting monomer in the presence of certain reagents. This way you can recycle many types of plastic materials such as polyesters, polyamides, polyurethanes, polycarbonates, etc. Because they have the active chemical and easily shared connection. These processes can be characterized general notion of solvolysis. Depending on the presence of any solvent to the reaction (alcohol, water...) speaks of the hydrolysis, alcoholysis, glycolysis, aminolysis or methanolysis.

Application of recycled materials obtained by this procedure so far is still limited. It is a known application procedure methanolysis or glycolysis in the processing of drinking bottles of PET. This procedure to obtain raw materials for hygienically clean PET and PUR, which can be used for packaging of foodstuffs.

Another group of chemical treatment processes include chemical reactions in which the macromolecules containing the plastic waste hydrocarbons can be obtained in the form of gas or oil, which can be further, processed in refineries petrochemical processes. This set of procedures can be performed reductive (e.g. Hydrogenation or pyrolysis) or oxidative (e.g. Obtaining synthesis gas) mode. These procedures are known as extrusion Degradation, hydrogenation, pyrolysis and gasification.

Incineration of plastic waste is intended to obtain heat. Direct use of oil for energy production from the point of "sustainable development" in the long run, does not make sense. Given that the products stored in plastic virtually total energy of oil, of great benefits that the energy accumulated oil in plastic products used for energy purposes, but only at the end of their life cycle. This method of using plastic waste should be applied only when it cannot be recycled in other ways.

Deposition. Since plastics are relatively new materials for a longer period of deposit are present many unknowns.

In foil and thin parts are already processes of decomposition, but did not show visible degradation phenomena. Found, also, that microorganisms do not have any influence on the decomposition of certain types of plastic materials such as PP (polypropylene) and PE (polyethylene), while in other species, e.g. with polystyrene or polyurethane they sped up the process of decomposition. 


\section{CONCLUSION}

Plastic materials with other waste, in the present conditions of our development, shall be deposited in landfills for municipal solid waste. It can be assumed that due to the decreasing space in the rapidly growing costs of future deposits and to present solutions for the disposal of waste will not be able to keep. It should be noted that the plastic materials in regulated landfills polluting the smallest streams (not dissolved in water) and do not pollute the air.

In contrast to materials whose recycling is done for economic reasons since ancient times, recycling of plastic materials is technologically and economically problematic, and in some areas is the subject of intense research. What is the procedure of processing to be applied, depending on the degree of dirt and sorted waste and the desired end product quality?

Processing of material melting process of the same type and pure plastic waste can be obtained recycles quality selection that can be used as a replacement for the original raw material, the same or similar quality. Such waste is generated in the production of plastic materials and production of the packaging.

Waste materials from household's characterized heterogenetic, and depending on the system of collecting, plastic materials contamination. Processing costs for a high value product, beyond the cost of new materials.

Technological solutions for processing mixed plastic waste were found (typically not sorted because of the demanding and expensive process of sorting and the lack of separation conducted by the consumer). However, the resulting recycles are lower quality and the market cannot compete with new material (and current production facilities are ready to expand its product portfolio and based on recycled materials).

The advantages of chemical treatment are the possibility of processing mixed plastic waste (often dirty), the saving of fossil fuel supply with the market for products, but currently high price does not cover the cost of recycling.
Processing procedures are considered one of the ways with which it can significantly alleviate a serious environmental problem, but only if it becomes profitable and industrial activity.

\section{REFERENCE}

1. N. Subara: "Ecology in traffic," CIP 502.17:656 628.2/.3 66074 COBISS. SR-SR-ID 134317836 ISBN 86-7307-190-9 "Želnid" Belgrade, 2006.

2. N. Subara, S. Stefanovic: Green logistics, TEHDIS, Belgrade, 2008.

3. N. Subara, S. Stefanovic: Traffic Ecology, Society for Energy Efficiency, Banja Luka, Serbian Republic, 2008.

4. S. Stefanovic, R. Cvejic: Environmental Management, TQM Center, Zrenjanin, 2009. 